\title{
Orbital Injury in Endoscopic Sinus Surgery for Sinonasal Inflammatory Disorders: Juntendo's Ten-Year Experience
}

\section{Katsuhisa Ikeda*, Shin Ito, Hirotomo Homma, Noritsugu Ono, Hiroko Okada, Yoshinobu Kidokoro, Akihito Shiozawa, Takeshi Kusunoki}

Department of Otorhinolaryngology, Juntendo University Faculty of Medicine, Tokyo, Japan

Email: ${ }^{\star}$ ike@juntendo.ac.jp

How to cite this paper: Ikeda, K., Ito, S., Homma, H., Ono, N., Okada, H., Kidokoro, Y., Shiozawa, A. and Kusunoki, T. (2017) Orbital Injury in Endoscopic Sinus Surgery for Sinonasal Inflammatory Disorders: Juntendo's Ten-Year Experience. International Journal of Otolaryngology and Head \& Neck Surgery, 6, 65-70.

https://doi.org/10.4236/ijohns.2017.65009

Received: August 15, 2017

Accepted: September 1, 2017

Published: September 4, 2017

Copyright $\odot 2017$ by authors and Scientific Research Publishing Inc. This work is licensed under the Creative Commons Attribution International License (CC BY 4.0).

http://creativecommons.org/licenses/by/4.0/

\begin{abstract}
Orbital injury and complications are commonly encountered in endoscopic sinus surgery (ESS) despite advances in techniques and instrumentation. For the recent 10 years, we summarized the experience of the rhinology unit of our department regarding orbital injury and complications of ESS for sinonasal inflammatory disorders. One thousand seventy-three patients (1869 sides) from January 1, 2003 to December 31, 2012 undergoing ESS for sinonasal inflammatory diseases were enrolled in the present study. The age of the patients ranged from 8 to 81 years, mean age 49 years. Orbital injury and complications were observed in 13 patients (13 sides), which corresponded to $0.7 \%$ of the operated sides and $1.2 \%$ of the patients. Eight patients showed herniation of orbital fat alone through the injury of the lamina papyracea. The protruding orbital fat was snipped and cut using forceps in 2 patients. Removal of exposed orbital fat using powered instruments was performed in 3 patients, two of whom transiently showed periorbital edema postoperatively. No permanent complications were observed. Meticulous preoperative and perioperative planning is critical to prevent orbital complications. Especially, exposure of the periorbit and herniation of orbital fat after lamina injury with powered instrumentation dramatically increases the potential for more severe complications.
\end{abstract}

\section{Keywords}

Orbital Injury, Orbital Complications, Endoscopic Sinus Surgery, Orbital Fat

\section{Introduction}

Endoscopic sinus surgery (ESS) has been widely accepted as a primary surgical 
modality for the treatment of inflammation, trauma, benign tumor, and fibro-osseous lesions [1]-[8]. However, complications in ESS are still encountered despite advances in techniques and instrumentation. It is critical to reduce major complications such as cerebrospinal fluid leak, intracranial injury, ocular injury, nasolacrimal duct injury, and massive bleeding requiring blood transfusion to reduce the risk of permanent injury, while a variety of minor complications of ESS include epistaxis, synechia, periorbital emphysema, hyposmia, antrostomy closure, etc. [9] [10]. The most common complications are known to be related to the ocular organ, which vary widely in severity and include orbital hematoma, subcutaneous or periorbital emphysema, diplopia and blindness, as well as postoperative hemorrhage [10].

For the 10 years from 2003 to 2012, we summarized the experience of the rhinology unit of our department regarding orbital injury and complications of ESS for sinonasal inflammatory disorders.

\section{Materials and Methods}

One thousand seventy-three patients (1869 sides) from January 1, 2003 to December 31, 2012 undergoing ESS for sinonasal diseases such as acute or chronic rhinosinusis, and paranasal sinus mucoceles were enrolled in the present study. The age of the patients ranged from 8 to 81 years, mean age 49 years. ESS in all cases was performed under general anesthesia. The ESS procedures in acute or chronic rhinosinusis and paranasal sinus mucoceles were performed according to our previous reports [1]-[8]. Since most of the CRS cases with nasal polyps associated with asthma showed extensive sinonasal disease with multiple polyps, which protruded from the olfactory cleft and middle meatus, we usually performed extended ESS. Extended ESS implies the elimination of polyps using a microdebrider, resection of the lower half of both the superior and middle turbinates, and maximal enlargement of each paranasal sinus ostium. This study was approved by the ethics committee of the Juntendo University Faculty of Medicine.

\section{Results}

Orbital injury and complications were observed in 13 patients (13 sides), which corresponded to $0.7 \%$ of the operated sides and $1.2 \%$ of the patients. All injuries and complications were brought about by injury of the lamina papyracea. Eight patients showed herniation of orbital fat alone through the injury of the lamina papyracea, where the presence of fat in the surgical field was confirmed by gentle ballottement of the eye (Figure 1). In another 2 patients, the protruded orbital fat, which was mistaken as nasal polyps, was snipped and cut using forceps (Figure 2). However, prompt recognition of the exposure of fat enabled us to prevent postoperative ocular symptoms and signs. Removal of the exposed orbital fat using powered instruments was done in 3 patients (Figure 3), two of whom showed periorbital edema postoperatively (Figure 4). However, no per- 
manent complications remained.

\section{Discussion}

ESS has the potential to cause orbital injury due to close proximity of the surgical site. Violation of the orbital medial wall can induce herniation of orbital fat, hemorrhage, extraocular muscle injury, ocular motility dysfunction, optic nerve injury, periorbital hematoma, or periorbital emphysema. In this series of our

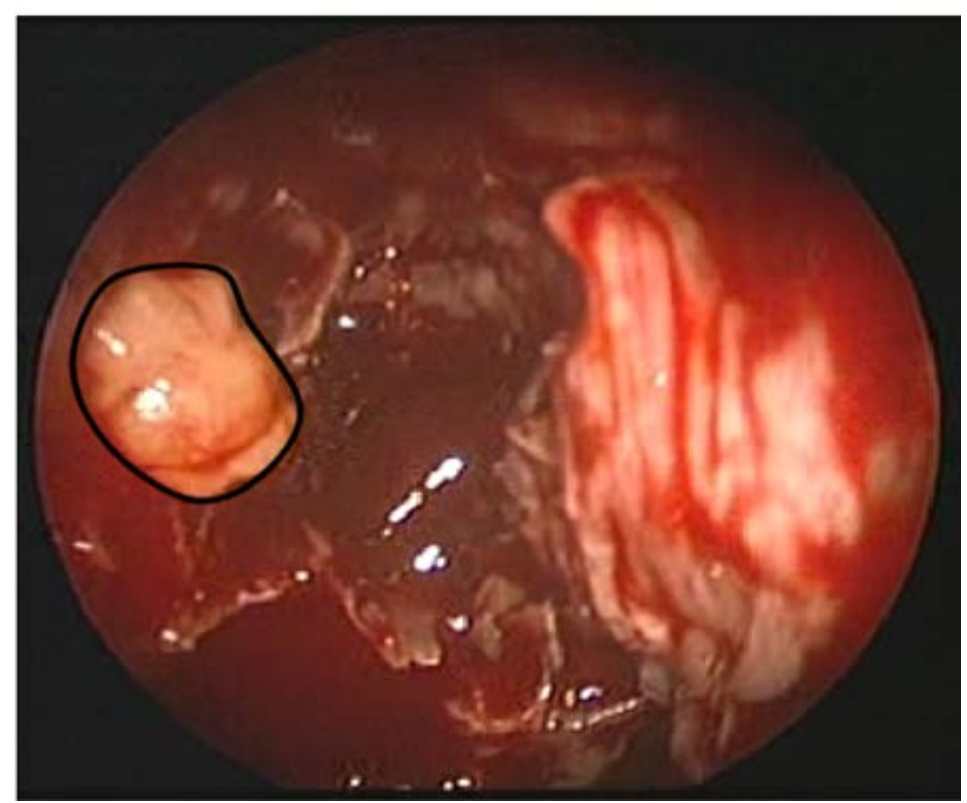

Figure 1. Herniation of orbital fat (a circle mark) in the right ethmoid sinus.

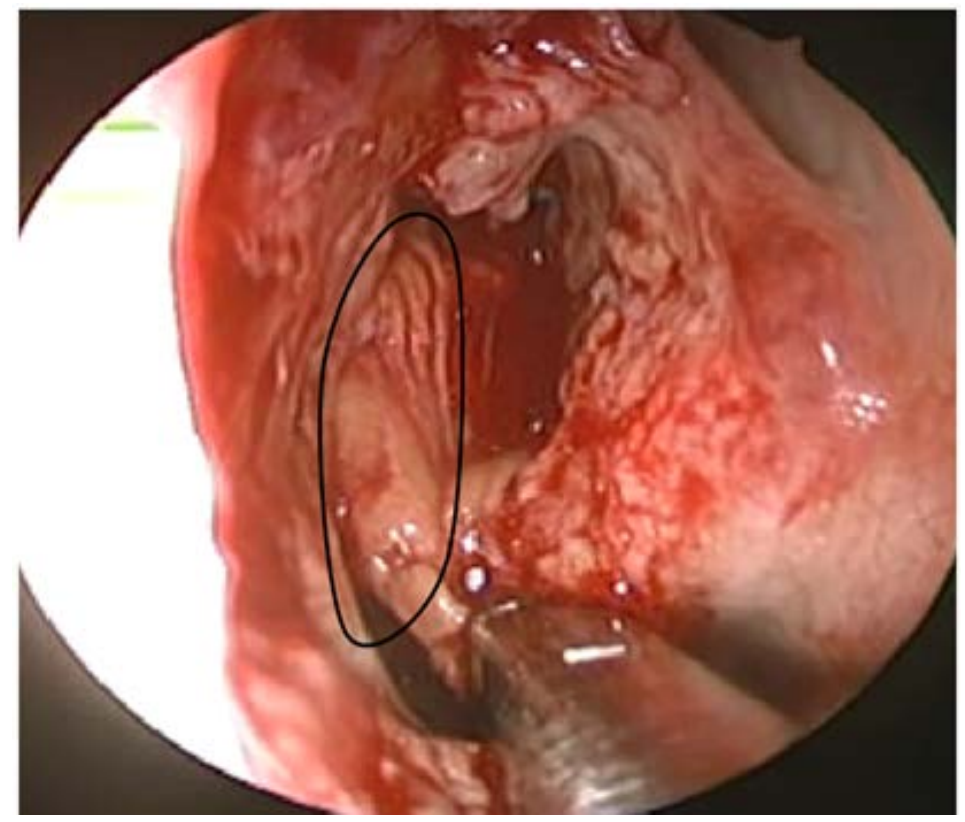

Figure 2. Snipping of the protruding orbital fat (a circle mark) using forceps in the right ethmoid sinus. 


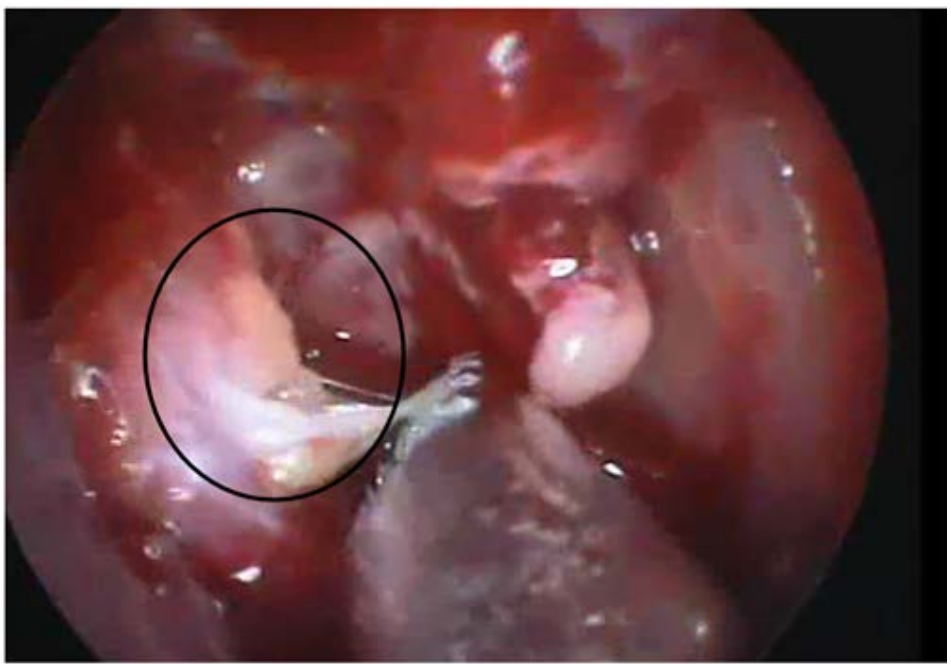

Figure 3. Removal of exposed orbital fat using powered instruments.

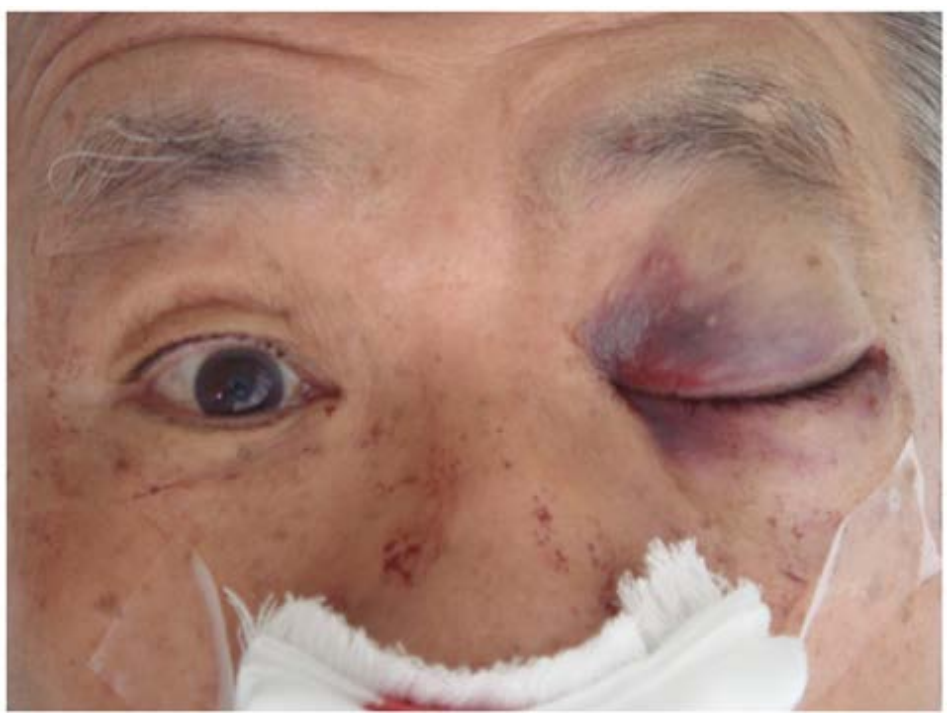

Figure 4. Postoperative picture showing left periorbital edema.

experience from the past 10 years, we experienced 13 patients (1.2\%) with ocular injury. However, postoperative complications were observed in only 2 patients $(0.2 \%)$, which was well comparable with that found in previous reports [11] [12] [13]. No major orbital complications such as blindness, double vision, ptosis, etc. were encountered in our series.

Meticulous preoperative and perioperative planning is crucial to prevent orbital complications. Preoperative review of the patient-specific anatomy should identify the location of the anterior and posterior ethmoid arteries, medial orbital slope and dehiscence, and atelectasis of the uncinated process using endoscope and radiological images. The appropriate surgical technique may also minimize the risk of ocular injury. Since blind insertion of a sickle knife into the infundibulum is associated with an inherent risk to the orbit, the uncinated process may be safely removed in a retrograde fashion with backbiting forceps [14]. 
It should be emphasized that exposure of the periorbit and herniation of the orbital fat after lamina injury with powered instrumentation dramatically increases the potential for a more severe complications. As the present study, orbital injury using conventional instrumentation may result in silent signs or minor complications. On the other hand, diplopia and blindness resulting from extraocular muscle injuries and/or orbital hemorrhage using powered instrumentation have been reported [14] [15]. Furthermore, subarachnoid hemorrhage has been reported as a complication of ESS using powered instruments [16]. Thus, the suction effect from powered dissection can draw in adjacent tissue and produce dramatic postoperative sequelae in a fraction of a second.

\section{References}

[1] Ikeda, K., Kondo, Y., Sunose, H., Hirano, K., Oshima, T., Shimomura, A., Suzuki, H. and Takasaka, T. (1996) Subjective and Objective Evaluation in Endoscopic Sinus Surgery. The American Journal of Rhinology, 10, 217-220.

[2] Ikeda, K., Hirano, K., Oshima, T., Shimomura, A., Suzuki, H., Sunose, H., Kondo, Y. and Takasaka, T. (1996) Comparison of Complications between Endoscopic Sinus Surgery and Caldwell-Luc Operation. The Tohoku Journal of Experimental Medicine, 180, 27-31. https://doi.org/10.1620/tjem.180.27

[3] Ikeda, K. and Takasaka, T. (1996) Endoscopic Laser Sinus Surgery Using KTP/532 Laser. Lasers in Medical Science, 11, 133-138. https://doi.org/10.1007/BF02133210

[4] Ikeda, K., Oshima, T., Furukawa, M., Katori, Y., Shimomura, A., Takasaka, T. and Maruoka, S. (1997) Restoration of the Mucociliary Clearance of the Maxillary Sinus Following Endoscopic Sinus Surgery. Journal of Allergy and Clinical Immunology, 99, 48-52.

[5] Ikeda, K., Suzuki, H., Oshima, T., Shimomura, A., Nakabayashi, S. and Takasaka, T. (1997) Endonasal Endoscopic Management in Fibrous Dysplasia of the Paranasal Sinuses. American Journal of Otolaryngology, 18, 415-418. https://doi.org/10.1016/S0196-0709(97)90064-8

[6] Ikeda, K., Suzuki, H., Oshima, T. and Takasaka, T. (1999) Endoscopic Endonasal Repair of Orbital Floor Fracture. Archives of Otolaryngology-Head and Neck Surgery, 125, 59-63. https://doi.org/10.1001/archotol.125.1.59

[7] Ikeda, K., Takahashi, C., Oshima, T., Suzuki, H., Satake, M., Hidaka, H. and Takasaka, T. (2000) Endonasal Endoscopic Marsupialization of Paranasal Sinus Mucoceles. The American Journal of Rhinology, 14, 107-111.

[8] Ikeda, K., Oshima, T., Suzuki, H., Kikuchi, T., Suzuki, M. and Kobayashi, T. (2003) Surgical Treatment of Subperiosteal Abscess of the Orbit: Sendai's Ten Year Experience. Auris Nasus Larynx, 30, 259-262. https://doi.org/10.1016/S0385-8146(03)00060-9

[9] Ulualp, S.O. (2008) Complications of Endoscopic Sinus Surgery: Appropriate Management of Complications. Current Opinion in Otolaryngology \& Head \& Neck Surgery, 16, 252-259. https://doi.org/10.1097/MOO.0b013e3282fdc3b2

[10] Stankiewicz, J.A., Lal, D., Connor, M. and Welch, K. (2011) Complications in Endoscopic Sinus Surgery for Chronic Rhinosinusitis: A 25-Year Experience. Laryngoscope, 121, 2684-2701. https://doi.org/10.1002/lary.21446

[11] May, M., Levine, H.L., Mester, S.J. and Schaitkin, B. (1994) Complications of Endoscopic Sinus Surgery: Analysis of 2108 Patients-Incidence and Prevention. La- 
ryngoscope, 104, 1080-1083.

[12] Cumberworth, V.L., Sudderick, R.M. and Mackay, I.S. (1994) Major Complications of Functional Endoscopic Sinus Surgery. Clinical Otolaryngology and Allied Sciences, 19, 248-253. https://doi.org/10.1111/j.1365-2273.1994.tb01225.x

[13] Stankiewicz, J.A. and Chow, J.M. (1999) Two Faces of Orbital Hematoma in Intranasal (Endoscopic) Sinus Surgery. Otolaryngology_Head and Neck Surgery, 120, 841-847.

[14] Graham, S.M. and Nerad, J.A. (2003) Orbital Complications in Endoscopic Sinus Surgery using Powered Instrumentation. Laryngoscope, 113, 874-878. https://doi.org/10.1097/00005537-200305000-00018

[15] Bhatti, M.T., Giannoni, C.M., Raynor, E., Monshizadeh, R. and Levine, L.M. (2001) Ocular Motility Complications after Endoscopic Sinus Surgery with Powered Cutting Instruments. Otolaryngology-Head and Neck Surgery, 125, 501-509.

[16] Berenholz, L., Kessler, A., Sarfaty, S. and Segal, S. (1999) Subarachnoid Hemorrhage: A Complication of Endoscopic Sinus Surgery using Powered Instrumentation. Otolaryngology-Head and Neck Surgery, 121, 665-667.

\section{Scientific Research Publishing}

\section{Submit or recommend next manuscript to SCIRP and we will provide best} service for you:

Accepting pre-submission inquiries through Email, Facebook, LinkedIn, Twitter, etc. A wide selection of journals (inclusive of 9 subjects, more than 200 journals) Providing 24-hour high-quality service User-friendly online submission system Fair and swift peer-review system Efficient typesetting and proofreading procedure Display of the result of downloads and visits, as well as the number of cited articles Maximum dissemination of your research work

Submit your manuscript at: http://papersubmission.scirp.org/ Or contact ijohns@scirp.org 